\title{
Cheating is the Name of the Game - Conventional Cheating Arguments Fail to Articulate Moral Responses to Doping
}
Authors' contribution:
A) conception and design of the study
B) acquisition of data
C) analysis and interpretation of data
D) manuscript preparation
E) obtaining funding

\author{
Ashkan Atry ${ }^{\text {A-D }}$, Mats G. Hansson ${ }^{\text {DE }}$, Ulrik Kihlbom ${ }^{\text {DE }}$ \\ Uppsala University, Sweden
}

ABSTRACT

One of the most common arguments in the discussion on doping is that it represents a form of cheating. In this paper it is argued that common doping-is-cheating arguments based on notions of rule-violation and unfair advantage are inadequate, since they treat cheating as distinct from the structure and the logic of competitive sport. An alternative approach to cheating in sport as regards performance enhancement will be offered based on the ethics of participation in interpersonal relationships. This participatory perspective points towards the need to broaden our conception of agency and moral responsibility in relation to doping, beyond the notion of the individual "drug-cheat" who acts in a vacuum.

KEYWORDS doping, cheating, unfair advantage, rule violation, interpersonal relationships

\section{Introduction}

Many of us respect and admire elite athletes for their level of excellence, determination and dedication, among their other venerable qualities, yet there is something genuinely upsetting about their moral failures. Doping, which seems to represent one such failure, is a severe failure. Doping may be defined as the use of illicit substances and methods to enhance one's performance (e.g., steroids, blood doping, and EPO). However, one may ask, what is the source of our (often strong) moral responses (resentment or indignation) to doping? There are certainly many ways of addressing this question, but if you ask the proverbial person on the street why doping is wrong, the most likely answer would be something like: doping is wrong because it is a form of cheating. Doping-is-cheating arguments indeed represent one of the most common rationales used against doping. Yet given the ubiquity and the significance of the concept of cheating in our everyday and moral lives, it is surprising how little attention it has been given in the literature (Schermer, 2004; Green, 2003). Consequently, the concept of cheating in relation to doping has not been subjected to the type of theoretical scrutiny it deserves.

Broadly speaking, cheating in sport is divided into three major categories: sabotage, doping, and match fixing, of which doping seems to constitute the biggest problem for the sport community (Preston \& Szymanski, 2003). Loland defines cheating in sport as: "an attempt to gain unfair advantage by violating the shared interpretation of the basic rules (the ethos) of the parties engaged without being caught and held 
responsible for it" (Loland, 2002, p. 96). Whatever definition of cheating one may adopt, approaching the issue of doping as a form of cheating raises two important questions:

1. In what sense, if any, can doping be said to represent a form of cheating?

2. If doping is a form of cheating, why is it wrong?

Addressing these questions in a persuasive and adequate way is a matter of utmost importance, since if we do not have a clear idea about the manner in which doping constitutes a form of cheating, how can we, based on that slippery ground, go on setting and implementing policies which address the issue of doping in a sensible manner?

Currently, there seem to be two predominant themes that frame doping-is-cheating arguments. According to these, doping could be said to represent a form of cheating, and hence be wrong, since it involves: a) breaking the rules, and b) gaining unfair competitive advantage that is not equally accessible to opponent(s). In this paper, it is argued that "cheating" should be understood as something internal to the structure and the logic of competitive sport, and not as something distinct from it. The two action-based understandings mentioned above are slippery and fail to cash out moral responses to doping as a form of cheating, since they 1 . Treat cheating as distinct from the structure and the logic of sport competitions; 2 . Involve internal inconsistencies which cannot be ignored, and, more importantly; 3. Ooverlook the important dimension of human interpersonal relationships, which provides the cradle and the very condition of possibility for the cheating phenomena. It is suggested that a shift of focus from on-the-field actions to human interpersonal relationships provides a better understanding of the dynamics of cheating in sport competitions and the related issues of moral responsibility and judgment.

Modern sport competitions can be understood as joint activities that involve interpersonal relationships between athletes, fans, coaches, managers, leaders, medical staff, promoters, organizers, sports organizations, etc. Cheating requires a minimum of two parties who stand in a certain type of relationship with each other, namely, the cheater(s) who could justifiably be morally responsible, and the victims(s) who could justifiably make claims on others to not be cheated upon (here, we set aside the notion of selfcheating). This implies a network of mutual claims and expectations embedded within the interpersonal relationships that underlie joint activities such as sports competitions. Understood in this light, it is argued that cheating can be understood both as failure to comply with pre-existing mutual demands to manifest goodwill towards other participants and those involved and as a breach of fundamental fairness requirements (understood in terms of mutual regard or respect) inherent in cooperative joint practices such as sports competitions (see Loland, 2002, pp. 41-106; Rawls, 1971, p. 343). Finally, given the alternative understanding of the dynamics of cheating presented here, it is concluded that conventional cheating arguments in general cannot convincingly and effectively address the complexity of doping phenomena in their contemporary (to a great extent) institutionalized form.

\section{Making sense of doping-is-cheating arguments}

\section{a) Doping is cheating because it involves violating the rules}

The use of some forms of performance enhancing methods and substances is against the established rules set by organizations such as the International Olympic Committee (IOC) and the World Anti-Doping Agency (WADA). If the rules prohibit the use of an enhancer in a particular sport (e.g., steroids, EPO, growth hormones, and amphetamine), then one may call the illicit use of this enhancer a form of cheating simply by referring to the existing rules; that is, it is cheating because it is a violation of the rules. However, as regards anti-doping rules, an obvious problem arises when determining whether the use of a newly developed (unlisted) enhancer constitutes a form of cheating in the above sense. In such cases, an appeal to existing rules would not settle the issue (Schermer, 2008). The enhancer in question may become prohibited by the introduction of new rules, which in turn require ethical justification. The process thus goes on. 
But what is it that renders rule violation in the case of doping a form of cheating? Rule violation could be understood in a logical, and a moral sense (Leaman, 2003). The logical sense refers to violating the constitutive rules (i.e., rules defining a particular sport). For instance, winning a foot race by riding a motorcycle involves violating the constitutive rules of foot racing and in a sense implies cheating the game itself (Schermer, 2008), since in doing so one is engaged in a different kind of sport than foot race. The moral sense refers to violating the regulative rules of a sport. Reducing the opponents' chance of winning by any form of sabotage, e.g., drugging the opponent before a match or simulating a foul by breaking a blood capsule in one's mouth, are examples of this that involve deceiving other competitors and match officials in order to gain unfair advantage over rule-abiding competitors. Doping, in our opinion, falls under the latter category of rule violation.

Nevertheless, it cannot be the mere fact of breaking the rules that qualifies it as a form of cheating; neither can it be the covertness or deception involved in doping behavior. This is because not all rule violations are cheating, and because some rule violations are done openly. Consider, for instance, the socalled tactical fouls where athletes break the rules by intentionally committing a foul and accepting the penalty, and all these are done openly. Intentional fouls involve breaking the rules, and though being considered wrong by some, they are not considered as a form of cheating (see Loland, 2005). As Jerzy Kosiewicz points out, "the main and the most important purpose of competition - both in pragmatic and axiological meaning - is not a strict adherence to the rules of the competition, but the optimal use of their content in order to achieve success" (Kosiewicz, 2011a, p. 38). Furthermore, not all forms of cheating involve breaking explicit rules. One may, for instance, view behaviors such as time killing in football or intimidating an opponent in tennis by repetitively tying one's shoelace as forms of cheating even though they do not involve breaking any explicit rules.

Another way to make sense of doping-as-cheating would be to say that doping is cheating since the doper, by violating the anti-doping rules, gains unfair advantage (Schermer, 2008), that is, a competitive advantage which is not accessible to rule-abiding competitors. However, one may argue that one way to avoid the issue of unfair advantage and cheating would be to change existing rules. Removing the current ban, or changing the rules in this regard, would lead to athletes having (more or less) equal access to performance enhancing substances. This would resolve the issue of cheating and fairness (Schneider \& Butcher, 2000; Savulescu et al., 2004; Foddy \& Savulescu, 2007; Nature Editors, 2007). If everyone would have equal access to enhancers, then doping would not constitute cheating. Moreover, one important aspect in implementing the rules is the principle of procedural fairness, i.e., that the rules are applied indiscriminately to everyone. Therefore, the issue is not only about ethical justification of the rules, but also about implementing them fairly and realistically. It becomes problematic when the rules no longer work the way in which they were intended. Anti-doping rules are supposed to be there to protect "clean" athletes, but when the majority of dopers manage to evade detection due to ever more sophisticated doping methods such as micro-doping, or due to flawed testing procedures (Lundby et. al., 2008), implementing the rules may actually end up favoring the "cheater", and this would be unfair to rule-abiding athletes who find themselves unable to compete with dopers on a leveled field.

In short, many forms of cheating may involve breaking rules; nonetheless, the rules in and of themselves do not seem to cash out our intuitive understanding of the moral wrongness of doping, and our moral responses to doping as a form of cheating. The focus on rules and penalties implies the idea that the main reason for athletes to refrain from cheating is the compliance to rules and evading penalties. Violating a rule is illegitimate only if the rule in question is legitimate. Either there are rational justifications that underlie anti-doping rules (e.g., as regards health and safety considerations), and if so, this point rather than the mere breaking of a rule makes doping morally wrong; or, if the rules are arbitrary, there is no reason for athletes to endorse them. Whatever one might think of the status of anti-doping rules, the wrongfulness of cheating in sports should clearly not be a mere bureaucratic question. This does not mean that there should be no rules regarding performance enhancement, but that if doping is a form of cheating, it should be prohibited because it is wrong, not wrong because it is prohibited. 


\section{b) Doping is cheating since it involves gaining unfair advantage}

There are different forms of cheating in sports competitions, such as sabotage and match fixing. Now, the question is whether cheating in the case of using enhancers (illicit drugs) amounts to the same kind of moral wrong as other forms of cheating, for instance, drugging the opponent prior to a match (sabotage)? Well, both cases seem prima facie to imply a notion of gaining unfair competitive advantage. The notion of unfair advantage constitutes one of the most common arguments against doping (Gardner, 1989). Sport competitions are about gaining advantage over one's opponent; it is part of the nature of sport competitions. Indeed, one may argue: "sports competition aims at not only showing inequality of opportunities but demonstrating and deepening - as far as possible - the real differences between competitors" (Kosiewicz, 2011 b, p. 78). Understood in this strictly pragmatic way, "it is advantage and benefit that matters, rather than autotelic values" (ibid, p. 85). Competitive advantage may be gained by a variety of means, e.g., training, coaching, equipment, diet, doping methods and substances, for which the athlete could be held responsible. Having a competitive advantage may also be due to the inborn inherited genetic predispositions and natural endowments for which the athlete herself is not responsible, e.g., height, muscle structure, oxygen-carrying capacity of the red blood cells, which affect endurance and fatigue. Some of these advantages are perceived as being fair (e.g., the advantage gained by training) and others (e.g., using steroids or EPO) as being unfair.

However, there are competitive advantages, which although being in one sense or the other considered "unfair", do not involve cheating. Imagine an athlete who gets better coaching: she may perform better than other equally talented athletes due to adopting more effective training methods available only to her. This, in a sense, could be seen as constituting unfair advantage but not an instance of cheating. Regardless of what one might think of the fairness of the situation, one could not say that she has done something wrong. Moreover, there seems to be a correlation between athletic achievement (e.g., Olympic medal counts) and gross domestic product (GDP) (Preston \& Szymanski, 2003). Some athletes may, due to genetic mutation, have red blood cells with unusually high capacity for carrying oxygen, which entails competitive advantage in sports such as cycling. Why, then, is it considered cheating if an athlete gains the very same advantage by using EPO or blood doping? Here, we may make a distinction between unfair-but-acceptable competitive advantages, and unfair-and-unacceptable advantages (see also Gardner, 1989). The tension between these two categories of competitive advantage renders doping-is-cheating arguments that are based on the notion of gaining unfair advantage slippery, since focusing merely on unfair advantage unearths tensions in modern sports that are hard to ignore and are difficult to account for in a consistent way. Here, our concrete responses could be indicative of our moral intuition in relation to performance enhancement. Thus, there could be gained competitive advantages that may be considered as "unfair" though not involving cheating and not raising genuine moral responses. It seems reasonable to suggest that the fairness or unfairness here is not a quality of the gained competitive advantage in itself (see also Gardner, 1989). In other words, gaining or possessing competitive advantage (even if in some cases "unfair") in and of itself does not qualify an action as being a form of cheating, and thus morally wrong.

Another related way of making sense of doping-is-cheating arguments is to say that doping is a form of cheating since it undermines the category of effort. An athlete who cheats on others (e.g., by taking the subway during a marathon), will be unjustifiably credited and awarded due to accomplishments that are the result of cheating or taking shortcuts, i.e., she does not deserve the merit since her achievement is no longer her own doing. In this view, doping could be said to represent a form of cheating in the sense of reducing the amount of individual effort to such a degree that the achievement no longer could be truly said to be the athlete's own doing.

In this account, it is not clear exactly in what way shortcuts are wrong vis-à-vis achievement. The basic structure and the logic of sports competitions include facing certain physical and mental challenges. It is not unreasonable to suggest that in sports competitions, as in any other instances of problem-solving and task-oriented accomplishments, intelligence and efficacy are of key importance. Shortcuts, understood in this regard, can be seen as part of the nature of sports competitions. Today, technological advances such as computers and sophisticated search engines help reduce the amount of effort a researcher exerts finding 
relevant articles, quotations, and references. Does this undermine academic achievement in any way, or render the use of technology a form of cheating? It does not seem so. The same holds for the technological and pharmacological advancements in relation to sport (e.g., as regards developing more effective training methods, diets, nutrition, or aerodynamic equipment), which in many cases aim to reduce the amount of effort. So, reducing the degree of effort (e.g., by taking shortcuts), does not always raise ethical concerns, nor does it by/in itself involve cheating. Rather, shortcuts to achievement could be perceived as cheating and wrong 1 . When they run counter to principles of fair competition, that is, when athletic achievement and the merit related to it is gained unfairly (e.g., taking another route than the prescribed race course); and/or 2. when they undermine the very purpose or the nature of a particular sport competition (e.g., using a jet engine to win a Formula-1 race). The latter could be understood as cheating the game itself by breaking the constitutive rules of the game (e.g., using subway to win a foot race) (see Schermer, 2008).

Current doping methods and substances do not altogether eradicate the element of effort. For example, even though steroids, which allow athletes to train harder, enhance athletic performance, the doper still has to work hard. Nor do steroids involve the logical sense of rule-violation discussed earlier (see ibid.). It doesn't make sense to say that a rider who has used steroids or EPO is no longer involved in cycling but some other activity. Quite the contrary, riders do dope in order to continue being contesters in cycling tournaments. It would be wrong to compare doping with using a motorcycle to win a race, though the comparison sometimes is made in the literature (e.g., Sandel, 2007; Gardner, 1989). What is more, achieving excellence in a particular sport could be much easier and may require less effort and hard work for some athletes than others. The reference to effort or hard work as a measure of what counts as adequate athletic achievement in the case of doping begs the question. It is not clear in what way doping represents a "shortcut" to achievement analogous to the use of a motorbike in a foot race. Effort, though being a necessary condition, is not sufficient for achieving excellence. Without possessing certain favorable inborn genetic predispositions, (and right coaching, etc.) a majority of us would not make it to the top, no matter how much effort we are prepared to put into it.

In summary, the categories of rule-violation and unfair-advantage-gaining seem unable to shed light in a consistent way on our moral intuitions about the ethical status of doping-as-cheating. These notions seem to be close to our moral intuitions in this respect. Yet the insurmountable difficulty in doping-is-cheating accounts is that it seems impossible to distinguish the relevant factors clearly enough without falling into inconsistencies or without facing unavoidable tensions (here we have attempted presented a sketch of the current doping-is-cheating arguments; for a more elaborated discussion see: Gardner, 1989; Schermer, 2008; Leaman, 2007; Green, 2004; Preston \& Szymanski, 2003). To explain and assess our intuitions and responses to the supposed moral wrongfulness of doping as a form of cheating, we need to focus on what, on a more fundamental level, provides the very conditions for cheating phenomena to occur in the first place, i.e., human interpersonal relationships. But let us first consider cheating in sport from a purely strategic and task-oriented perspective

\section{The grey zone between cheating and strategic planning}

During the Tour de France in 2003, the American cyclist Lance Armstrong did something extraordinary when he was forced from the prescribed race route into a field in order to avoid a crash with another already fallen cyclist, Joseba Beloki. Instead of returning to the race route, which included an upcoming switchback, Armstrong decided to continue to ride across the field. He carried his bike up a small bank to reach the road, crossed it - in the process making the group check their speed slightly in order to avoid crashing with him on his return - and then remounted his bicycle. By acting thus, Armstrong

1. Clearly violated Article 18 of the Tour's rules which prohibits taking routes other than the prescribed racing course, and

2. He literally took a shortcut (avoiding the switchback) which theoretically might have affected the results by putting him in an unfair competitive advantageous position. 
The above factors (breaking the rules, affecting the results by taking shortcut, and gaining unfair advantage) could qualify his action as a form of cheating. Nonetheless, he avoided penalties. Some called his action "cheating", but many cycling fans and commentators instead deemed or interpreted his maneuver as a display of athletic skillfulness and admired his sense of coolness, determination, and control in handling the situation. Moreover, the judges issued no penalties. Now, almost a decade later, following the US AntiDoping Agency's (USADA) recent report, Armstrong has been accused for being a "drug-cheat", and, given his recent public confession, he was most probably on a full doping regime (steroids and EPO) during this Tour. This fact raises a question: Is there any relation between our ethical assessments of, and responses to, Armstrong's crossing the field as described above, and his doping behavior? It seems so. Doping-is-cheating arguments commonly rely on factors such as rule-breaking, unfair-advantage-gaining, and taking shortcuts. Yet as the cases of Armstrong indicate (riding across the field and being doped), relying solely on these onthe-field elements does not always cash out our moral responses to cheating in sport.

The wrongfulness of cheating and our genuine moral responses in this regard seem to amount to something more. It could, however, be argued that the two cases above involve offenses with different degrees of severity, that the latter is not comparable with the former, and that they motivate different degrees of moral responses accordingly. Yet, we should note that in this particular case we are talking about the Tour de France, perhaps the most prestigious cycling tournament where there is tremendously much (economically or otherwise) at stake, and, more importantly, where seconds are decisive when it comes to winning. In this sense, the cases above (doping, and crossing the field) could have affected the results in an equally decisive manner.

Today, many elite sports could, arguably, be seen as a form of task-oriented social practice. Due to increased professionalization and commercialization, sport has become for many elite athletes the only source of income and, in a sense, a job. To take an example: sports championships such as the English Premier League now represent multi-billion dollar enterprises. For a professional football team, much is at stake in order to maintain its position in such leagues. This requires, among other things, cooperation, intensive strategic planning, deploying effective methods of implementing these strategies, and gaining competitive advantage whenever the opportunity presents itself. The categories above, together with the underpinning rules and norms of a game, constitute a shared (implicit or explicit) practical-theoretical body of knowledge. The implementation of this body of knowledge requires a level of efficiency and intelligence on the part of individuals and the group as a whole in order to accomplish a common goal, namely, that of winning the championship (or, at least to retain a desired ranking). Excellence in sport includes the notion of being a strategically competent athlete. Thus, winning a football championship or a cycling Tour amounts to much more than simply following the rules of the game. It also involves the cooperative accomplishment of a task based on the requirements of intelligence (i.e., the capacity of understanding and solving particular problems in competitive settings) and efficiency (i.e., solving the problem in a most efficient and successful way).

Within this framework of task-oriented cooperative accomplishment in competitive settings, many stances of "cheating" (understood in a non-moral sense), such as Armstrong's case presented earlier, could be traced back to the strategic planning to gain competitive advantage and to deal with different (and sometimes new) challenges posed by the competition, in accordance to the requirements of intelligence and efficiency. This renders "cheating" a part of the strategic structure and the logic of sports competitions. A rule-governed game in itself includes and provides the conditions for cheating (both logically and practically). A competition that aims at determining who can run fastest from point $\mathrm{A}$ to point $\mathrm{C}$ via point $\mathrm{B}$ includes the possibility of taking a shorter and more effective direct course from point A to point $\mathrm{C}$.

What's more, from this perspective, the emergence of new circumstances and challenges in competitions may yield to the modification of the current rules. As Kosiewicz points out:

"Rules of the competition might - according to those involved in a particular sport-create a corset that restricts creativity, as well as too harshly and too oppressively hampers the progress, approach, and eventual achievement of the pursued objectives. To act against the 
rules is to manifest a desire for freedom, for liberation from imposed and sometimes irrational constraints. These actions can contribute to adjustments in the regulations, to the tightening or easing of rules occurring in the regulations; it might lead to the incorporation of changes of a nature too difficult to predict" (Kosiewicz, 2011a, p. 35).

This renders mindful revisions of the rules inherent to the practice of sport. Athletes are not ruleabiding robots. They also create norms and values in sport, and as such must be given the opportunity to reasonably criticize rules which hinder them from implementing efficient and rational strategies to achieve tasks. However, to complete the picture, the above categories of efficiency and intelligence must be integrated with the norms of fair competition. Implementing certain strategies, even if they satisfy the requirements of intelligence and efficiency, may nevertheless run counter to the norms of basic fairness and a web of mutual demands and entitlements that are embedded within the realm of general human interpersonal relationships.

\section{Moral responsibility and moral responses to cheating in sport}

Modern elite sport competitions can be seen as rule-governed joint activities that require a level of mutual (not necessarily equal or symmetrical) cooperation. The cooperative nature of competitions goes beyond the individual athletes and could be said to also involve cooperation among different involved parties (athletes, spectators, referees, coaches, organizers, fans, sports organizations, sponsors, media, etc.) in order to make the practice of sports competitions possible. Some degree of cooperation and the existence of a relatively stable set of rules are necessary conditions for having a meaningful conception of competition, and/or of winning. Cooperation also entails interpersonal relationships, which include interactions among participants and others involved in sport competitions. This cooperativeness requires that individuals as rational agents who are involved in sport or are directly affected by the outcome of the competition, while pursuing their individual goals must at the same time presuppose the existence of mutual relationships among one another. In such mutual relationships, the actions of individuals reciprocally affect and condition each other. As concerns cheating in sport, it presupposes the violation of a certain normative order that governs the practice, as well as moral agents who are engaged in interpersonal relationships with other agents, and who may reasonably be held responsible. Given the participatory nature of sports competition, which involves interpersonal relationships, it is not unreasonable to suggest that the practice of sport comes under the same moral requirements as participating in any other joint social activity (see Leaman, 2007). Put in the context of human interpersonal relationships, our concrete responses to others' mischief provide a valuable source to understanding our moral intuitions in relation to cheating behavior and moral responsibility in sport.

An approach to the relation between the notion of moral responsibility and our concrete reactions to others' actions is provided by P.F. Strawson in his influential essay "Freedom and Resentment." Though Strawson himself does not address the issue of cheating, one may nevertheless develop an account of cheating within the context of his participatory ethics. In this light, sport competitions could be seen as joint social activities that involve a system of mutual demands (e.g., not to cheat one another) and entitlements (e.g., not to be cheated) among participants. Given this system, we argue that "cheating" could be construed as a structural element within the social practice itself and not as something distinct from it.

Here we do not have the space to present Strawson's rather complex account in an adequate way. Instead, we will confine ourselves to present the outlines of his account relevant to our current purpose (for a more detailed analysis see Darwall, 2004; Wallace, 1994). Strawson argues that when we hold people morally responsible, there are certain emotional responses that underlie our judgment or assessment that he calls reactive attitudes (Strawson, 2004). For instance, we may feel resentment towards a person who has cheated us, or feel moral indignation towards a person who cheats on others. According to Strawson, reactive attitudes, such as blame, indignation, or resentment are to be understood as distinct affective states that are indistinguishable from holding a person morally responsible. Strawson himself seems to be reluctant to offer 
a strict definition of reactive attitudes (Strawson, 1980, p. 226), but rather emphasizes the role they play (or, perhaps, the function they have) in interpersonal relationships. He describes reactive attitudes as "nondetached attitudes and reactions of people directly involved in transactions with each other"; that is, "attitudes and reactions of offended parties and beneficiaries", attitudes such as "gratitude, resentment, forgiveness, love, and hurt feelings" (Strawson, 2008, p. 5).

Reactive attitudes, such as resentment and gratitude, are affective states that are intentional. As such, they presuppose the context of participation in human interpersonal relationships (ibid., p. 9). This point distinguishes reactive attitudes from a range of object-related emotional responses that one might have: for instance, the rage one might feel against a computer that does not function properly. Thus, reactive attitudes make sense only from the perspective of participation and involvement with others. These are primarily attitudes towards the actions of rational agents with whom we are, in one way or another, involved and whom we may hold morally accountable, and to whom we may account for, in that their actions may affect us and vice versa. To this Strawson contrasts what he calls the "objective attitude", that is, when we no longer conceive of a person as fully qualifying for being a rational (co-) agent in the above sense, and therefore not a proper target of reactive attitudes such as resentment or indignation (e.g., young children, insane persons, or people in stress).

Roughly speaking, objective attitudes can be seen as some sort of "excuse" or justification for the behavior of a person who in one sense or another could not be held responsible and requires either a permanent or temporary suspension of reactive attitudes of resentment and indignation. As such, objective attitudes are divided into two categories: 1 . When we consider a person as being generally an inappropriate target of reactive attitudes (e.g., when the wrongdoer is insane), and 2. When the reactive attitudes towards a person ought to be suspended temporarily due to particular circumstances (e.g., when we find out that the wrongdoer has been coerced or has been stressed). In the latter category, one still perceives the wrongdoer as a responsible agent in general, but adopting an objective attitude towards her in this case entails altering our judgment about her action due to particular circumstances. For instance, we may excuse a person who behaves inappropriately towards us due to stress; nevertheless, we do still conceive her as a rational and fully responsible agent under normal circumstances. This is not so with respect to insane persons, in that they are generally excluded from the moral community of rational agents who could justifiably be held responsible. This double feature links reactive attitudes with intentional agency and distinguishes them from a range of emotional responses towards others that do not involve or presuppose intentional agency (e.g., feeling envious towards a person who owns a better car than one's own).

Reactive attitudes furthermore involve mutual demands that one legitimately makes on another to manifest good will (ibid, pp. 5-7). Simply put, A is entitled to make a legitimate claim on B to manifest good will towards A and others; the same goes for B. As an example, Strawson discusses resentment that according to him is an appropriate reaction to actions of people who fail to manifest goodwill towards us (ibid, p. 6). So understood, reactive attitudes could also be seen as responses or reactions towards the way in which the other exhibits her attitude towards the system of mutual demands and her regard for us as a person. According to Darwell, reactive attitudes could be seen as embodying a sense of mutual respect or regard (Darwell, 2004). Moreover, one may suggest that another aspect of reactive attitudes is that they differ from more or less unreflective or immediate positive or negative emotional responses to the actions of others. Reactive attitudes, in their intentionality, concern more than only actions (in our case, gaining advantage, or rule violation) and also concern the person and the degree of the good will (or the lack of it) manifested in her actions. Responses to moral failure of a person in this regard could be understood as evaluating the person's quality of will manifested in her actions against the background of the general system of mutual demands and entitlements.

It must be noted that Strawson's account does not presuppose a specific system of moral demands. Rather, it is this web of human interpersonal relationships that constitutes the foundation and the elementary cement of our moral/social life: 
"In the absence of any forms of these attitudes it is doubtful whether we should have anything that we could find intelligible as a system of human relations, as human society" (Strawson, 2008, p. 26).

Strawson's account could be interpreted as seeking the grounds of morality in the rudimentary cell of human practices, that is, the relationships between persons and the rather mundane ways of managing these relationships. The above web of mutual demands (or expectations) and entitlements represents an organization or structure that is indispensable to social relationships. In other words, the web of mutual demands represents the possible condition for social relationships, and not necessarily their outcome. Thus, one may suggest that a person qua person (or qua human being), and as a member of the moral community, is, as it were, a party engaged in the system of mutual demands by default.

In summary, Strawson's account could be rendered as follows. As social beings, people participate in various forms of relationships with each other. These participatory relationships involve interactions among individuals made up of a general system of mutual justifiable demands or claims for manifesting good will. Against the background of this general system of mutual demands, reactive attitudes may be understood as emotionally charged evaluations of an agent's attitude and the quality of her will, which is manifested in her actions towards us and towards others. Regarding persons as fully free and responsible (co-) agents involves, from the perspective of participation, resenting them when they fail to manifest goodwill in their actions towards others or us. Arguably, in Strawson's participatory ethics one finds a very basic notion of fairness. This notion implies mutual respect, seeing the other qua person who can put legitimate demands on us, and a sense of equality among persons in realizing each other's equal capacity of having legitimate entitlements and issuing legitimate demands. This, one could maintain, constitutes a fair ordering of interactions among participants.

Given what has been said, the act of cheating in cooperative social activities could be understood as a failure to comply with the system of mutual demands and entitlements as sketched out above. Put in this perspective, cheating can be seen as a structural element in the system itself. This in the sense that the whole procedure of planning and implementing the act of cheating is possible if and only if the cheater himself or herself a) assumes the existence of a binding system of mutual entitlements in a system that s/he tacitly intends to take advantage of, and b) presumes that others would both comply with the normative requirements and assume responsibility for them in this regard. If this is the case, the cheater who defies the system of mutual demands and entitlements, and who intends to take advantage of it, by the same token implicitly assigns validity to the system. If all participants equally recognize the existence and the validity of the system of mutual demands and entitlements, and if the existence of this system is a necessary condition for the planning and implementation of the strategic act of cheating, it could be concluded that cheating represents a constitutive element within the system itself. In other words, wherever there is a joint social practice that involves a system of equally recognized mutual demands and entitlements, there is always the inherent (at least logical, or thinkable) possibility for strategic acts of taking advantage of the system (e.g., in the form of free riding, or cheating).

Athletes do not cheat for the sake of cheating. Cheating in sport competitions can be seen as strategic acts that in many cases are a part of the structure of sport competitions and which aim at gaining competitive advantage over others. However, the target of our possible reactive attitudes towards cheating (i.e., blame, resentment, and indignation) can be properly understood neither in terms of the action itself (e.g., violating the rules) nor in terms of the gained competitive advantage. Rather, it is the quality of the supposed cheater's attitude and will towards us, or towards others, which is manifested in her actions. A cheating act may evoke reactive attitudes of resentment or indignation even if it does not result in gaining a competitive advantage, for instance, when an illicit substance is taken in belief that it provides performance enhancement, while in reality it has no enhancing effect whatsoever. In such a case, one could say that the unfair advantage is basically taken from the system of mutual demands and entitlements itself, even if gaining unfair advantage in terms of performance does not occur. While the unfair-advantage argument fails in situations where doping is pervasive, this Strawson-inspired account holds even in those situations, since the unfairness of the 
situation is no longer only a quality of the advantage in question but an element of the underlying web of interpersonal relationships. Even in a full-blown cheating culture, cheating can be understood as failure to manifest goodwill towards other parties who are involved in sport (e.g., the fans).

In the case of Armstrong mentioned earlier (crossing the field), judges deemed his action in this particular circumstance as a case of "inadvertent cheating", whatever that means. Nevertheless, in Armstrong's case we have the act itself, which includes taking (unfair) advantage and breaking a rule, but here the act in itself is not enough to evoke reactive attitudes of resentment, blame, or indignation, since the quality of the will manifested in the action does not render it a proper target of these reactive attitudes. Instead, one could suggest that in a sense our responses in this case coincide with Strawson's notion of objective attitudes. We hold Armstrong responsible for what he did, and we think that taking short cuts from the racing route is unfair and wrong, yet we do not find his will a proper target of reactive attitudes. Moreover, in adopting such a detached objective attitude towards Armstrong's action, admirable athletic qualities such as strategic competence and self-possession come to the light, which evidently can evoke attitudes of praise. Unfortunately, one could not say the same about his now known systematic doping behavior over the last decade (USADA report, 2012).

\section{In what sense then is doping cheating?}

We have attempted to approach cheating in sport from the perspective of human interpersonal relationships. We claimed that cheating can be understood as the failure to manifest goodwill towards other participants in joint activities such as sport competitions. The question remains: In what way this alternative understanding can reinforce the doping-is-cheating arguments as a convincing objection to doping? Before addressing this question, a reality check is due. Today, it is clear to many that the use of performanceenhancing substances is epidemic (Lippi et al., 2008; National Center on Addiction and Substance Abuse, 2000), and it is only going to get worse due to the prospect of genetic enhancement (Adam, 2001). Many athletes manage to pass the tests partly due to the flaws in testing procedures (ref), and partly due to development of ever more sophisticated doping methods and masking agents. Empirical studies (e.g., Lippi et al., 2008), recent confessions of athletes (Hamilton \& Coyle, 2012), and the recent USADA investigation (USADA report, 2012) all indicate that the phenomenon of doping is much more complicated than other forms of cheating in sport, such as match-fixing and sabotage. Indeed, in light of recent findings, it would be naïve to think that doping is simply about a small group of athletes cheating other otherwise rule-abiding athletes in order to gain unfair advantage.

Accusing a professional athlete of being a "drug-cheat" is a serious allegation with enormous consequences for the athlete both on a personal and a professional level, and for the sport community at large. The complexity of the doping phenomena in contemporary modern sports makes it difficult to pinpoint the appropriate target of our reactive attitudes towards doping behavior. Consequently, this leads to a sense of confusion as regards the scope of moral responsibility. This as opposed to clear-cut cheating cases such as simulating a foul by breaking a blood capsule in one's mouth, or drugging one's opponent prior to the competition. As the case of Armstrong clearly indicates, sophisticated forms of doping involve - in addition to the athlete - many other people on whom the athlete relies, that is, physicians, sponsors, managers, coaches, logistic, medical staff, etc. Thus, here the target of reactive attitudes is no longer a single will, or the attitudes of a single moral agent, but rather a form of multi-agency, or a multitude of wills, i.e., a multitude of actors and involved parties holding different positions as regards moral responsibility depending on the extent of their involvement.

It is thus hard to see who exactly is the appropriate target of our reactive attitudes in the case of doping. It could be argued that the athlete makes the ultimate decision; hence, she bears the ultimate moral responsibility. Nevertheless, as we have argued elsewhere (Atry et al., 2012), there are other factors beyond the individual athletes that may influence their rule-violating behavior, a point which has also been indicated by empirical studies about athletes' decisions to dope (Hardie et al., 2010, pp. 63-64). If so, how could we 
justifiably hold athletes who have been coerced as morally responsible and view them as an appropriate target of reactive attitudes of blame, resentment, or indignation? Empirical studies indicate that where doping is prevalent athletes indeed no longer perceive their doping behavior, as well as others', as a form of cheating, but as a (sometimes, the only) way to remain in competitions and to continue with the sport they love (Moran et al., 2008). In such cases, some athletes feel themselves rather being "cheated" if they do not dope (ibid.) One may say that in such a situation cheating as a moral category is lost for doping, since the conception lacks a sensible meaning in relation to doping, and can no longer be used to adequately frame a group of behaviors and attitudes.

Putting cheating in the broader context of human interpersonal relationships broadens the scope of moral responsibility. Doping-as-cheating and the scope of moral responsibility are no longer confined to the on-the-field notion of cheating and the related factors such as competitive advantage, and rule violation. Athletes not only have a moral responsibility towards each other in the game (not to take unfair advantage, not to violate the rules, etc.), they also have moral responsibility towards the athletic community. Thus understood, the scope of moral responsibility stretches beyond the competition itself. This perspective also allows for including the spectator's perspective, that is, the notion of fans being cheated, or the failure to manifest goodwill towards spectators who watch a game believing that the results reflect athletic excellence in form of a combination of training effort and natural talent, and not, say, in the form of who has the most means to deploy the best doping regime money can buy. This also includes the moral responsibility of the spectators and the sport community at large. One cannot demand extraordinary performances, such as the almost inhuman performances displayed in the Tour de France during the Armstrong era, and then just call the people who in a sense attempted to meet those expectations "drug-cheats". That said, many of us (the authors included) conceive of doping as something wrong on different levels, i.e., with regard to health risks, as corrupting the sport itself, or as undermining the status of sport as a source of moral education for the youth. What we whish to stress is that if our arguments as regards doping as a form of cheating are to be persuasive and consistent, we must first of all be clear about the sphere of moral responsibility in this respect. In other words, we must first begin by asking who's cheating whom, and who is the proper target of our reactive attitudes.

In conclusion, doping could be considered wrong for varieties of reasons (e.g., health risk for dopers themselves and adolescents who hold them as their role models). However, common doping-is-cheating arguments appear to be slippery when pressed; they are thus inadequate in addressing the issue of doping. This is partly due to failure to perceive cheating as a part of the structure and the logic of competitive sports. If we conceive of doping as an issue in sport, we need stronger and more persuasive arguments other than the conventional notions of doping-as-cheating. The alternative participatory perspective, presented here, points towards the need to broaden our conception of agency and moral responsibility in relation to doping, beyond the notion of the individual "drug-cheat" who acts in a vacuum.

\section{REFERENCES}

Adam, D. (2001). Gene Therapy May be Up to Speed for Cheats at 2008 Olympics. Nature. 414:6864:569-570.

Atry, A., Matsson, H.G., Kihlbom, U. (2012). Beyond the Individual: Sources of Attitudes Towards Rule Violation in Sport. Sport, Ethics and Philosophy, 6(4), 467-479. DOI:10.1080/17511321.2012.739194.

Darwall, S. (2004). Presidential Address to the Central Division of the American Philosophical Association. Retrieved from http://www-personal.umich.edu/ $\square$ sdarwall/

Foddy, B., Savulescu, J. (2007). Ethics of Performance Enhancement in Sport: Drugs and Gene Doping. In R. E. Ashcroft, A. Dawson, H. Draper, and J. R. McMillan (Eds.), Principles of Health Care Ethics (pp. 511-519). London: John Wiley and Sons.

Gardner, R. (1989). On Performance-Enhancing Substances and the Unfair Advantage Argument. Journal of the Philosophy of Sport, 16(1), 59-73

Green, S.P. (2004). Cheating Law and Philosophy, 23, 137-85.

Hamilton, T., Coyle, D. (2012). The Secret Race. Bantam, USA. 
Hardie, M., Shilbury, D., Ware, L., Bozzi, C. (2010). I Wish I was Twenty One Now - Beyond Doping in the Australian Peloton. Retrieved from http://www.newcykllingpathway.com

Kosiewicz, J. (2011a). Foul Play in Sport as a Phenomenon Inconsistent with the Rules, yet Acceptable and Desirable. Physical Culture and Sport. Studies and Research, 52, 33-43. DOI: 10.2478/v10141-011-0012-x.

Kosiewicz, J. (2011b). The Ethical Context of Justifying Anti-Doping Attitudes: Critical Reflections. Physical Culture and Sport. Studies and Research, 53, 76-92. DOI: 10.2478/v10141-011-0024-6.

Leaman, O. (2007). Cheating and Fair Play in Sport. In W.J. Morgan (Ed.), Ethics in Sport. USA: Human Kinetics.

Lippi, G., Franchini, M., Guidi, G.C. (2008). Doping in competition or doping in sport? British Medical Bulletin, 86, 95-107.

Loland, S. (2002). Fair Play in Sport: A Moral Norm System. London \& New York: Routledge.

Loland, S. (2005). The Varieties of Cheating-Comments on Ethical Analyses in Sport. Sport in Society, 8(1), 11-26.

Lundby, C., Achman-Andersen, N.J., Thomsen, J.J., Norgaard, A.M., Robach, P. (2008). Testing for recombinant human erythropoietin in urine: problems associated with current anti-doping testing. J Appl Physiol, 105(2), 417-9.

Moran, A., Guerin, S., Kirby, K., MacIntyre, T. (2008). The Development and Validation of a Doping Attitudes and Behaviour Scale. Report to World Anti-Doping Agency \&The Irish Sports Council.

National Center on Addiction and Substance Abuse (2000). Winning at All Cost: Doping in Olympic Sports (p. 2). National Center on Addiction and Substance Abuse at Columbia University. New York: NY,

Preston, J., Szymanski, S. (2003). Cheating in Contests. Oxford Review of Economic Policy, 19(4), 612-624.

Sandel, M.J. (2007). The Case against Perfection Ethics in the Age of Genetic Engineering. USA: Harvard University Press.

Savulescu, J., Foddy, B., Clayton, M. (2004). Why we should allow performance enhancing drugs in sport. British Journal of Sports Medicine, 38, 666-670.

Schermer, M. (2008). On the argument that enhancement is "cheating'. J Med Ethics; 34, 85-88.

Schneider, A.J., Butcher R.B. (2000). A philosophical overview of the arguments on banning doping in sport. In T. Tännsjö, C.M. Tamburrini (Eds.), Values in Sport: Elitism, Nationalism, Gender Equality, and the Scientific Manufacturing of Winners (pp.185-199). London: Routledge.

Strawson, P.F. (1980). Reply to Ayer and Bennett. In Z. Van Straaten (Ed.), Philosophical Subjects. Oxford: Clarendon Press.

Strawson, P.F. (2008). Freedom and Resentment. In Freedom and Resentment and Other Essays. New York: Routledge. USADA (2012). Report on Proceedings Under The World Anti-Doping Code and the USADA Protocol.

Wallace, R.J. (1994). Responsibility and the Moral Sentiments. Cambridge, Massachusetts: Harvard University Press.

\section{AUTHOR'S ADDRESS: $\quad$ Ashkan Atry}

Department of Public Health and Caring Sciences

Centre for Research Ethics \& Bioethics

Uppsala University

Box 564

SE-751 22 Uppsala, Sweden

Email: ashkan.atry@crb.uu.se 